\title{
Characterization of the powder obtained from wasted tires reduced by pyrolysis and thermal shock process
}

\author{
R. Mis-Fernandez'; J.A. Azamar-Barrios², C.R. Rios-Soberanis' \\ ${ }^{1}$ Centro de Investigación Científica de Yucatán, Unidad de Materiales \\ Calle 43, No. 130, Colonia Chuburná de Hidalgo, C.P. 97200 \\ Mérida, Yucatán, México \\ ${ }^{2}$ Centro de Investigación y Estudios Avanzados (CINVESTAV) \\ Unidad Mérida Km. 6 Antigua carretera a Progreso \\ Apdo. Postal 73, Cordemex, 97310, Mérida, Yuc., Méx.
}

\section{ABSTRACT}

This paper reports on the physicochemical characterization of solid powder obtained directly from wasted tires through pyrolysis and thermal shock process. Two different processes to reduce wasted tires were performed in order to acquire the residuals in powder to be characterized and compared. During this research, three phases were observed when pyrolysis was applied to rubber: the first one a solid black phase formed by organic and inorganic compounds such as zinc oxide (ZnO) and zinc sulphur (ZnS); secondly a gaseous phase containing hydrocarbons i.e. aromatic compounds and, finally, a liquid phase formed by heavy and light oils. By using X-ray diffraction technique, the relationship between temperature and the presence of inorganic compounds was determined varying the temperature of pyrolysis. In addition to X-ray diffraction, infrared spectroscopy, thermal analysis and scanning electron microscopy were used to fully characterize the samples. Comparing the results observed in both processes, it was found that thermal shock process presents some advantages over the pyrolytic, i.e. energy consume and solid black phase production; however, by pyrolytic degradation a powder richer in carbon compounds is obtained.

KEYWORDS: Pyrolysis, thermal shock, characterization techniques.

\section{RESUMEN}

Este artículo se enfoca en la caracterización fisicoquímica del polvo sólido obtenido directamente de la reducción de llantas de desecho por medio de las técnicas de pirólisis y de choque térmico. Dos diferentes procesos para reducir las llantas usadas fueron realizados con el objeto de obtener los residuos en polvo para ser caracterizados y comparados. Durante esta investigación se observaron tres fases cuando la pirólisis era aplicada al hule: la primera, una fase sólida negra conformada por compuestos orgánicos e inorgánicos tales como el óxido de zinc ( $\mathrm{ZnO})$ y sulfuro de zinc ( $\mathrm{ZnS}$ ); en segundo lugar, una fase gaseosa conteniendo hidrocarbonos (compuestos aromáticos) y finalmente una fase líquida formada de aceites ligeros y pesados. Empleando la técnica de difracción de rayos $X$ se determinó la relación entre la temperatura y la presencia de compuestos inorgánicos al variar la temperatura de pirólisis. Espectroscopía de infrarrojo, análisis térmicos y microscopía electrónica de barrido fueron utilizados adicionalmente para caracterizar las muestras. Comparando los resultados observados en ambos procesos, se encontró cierta ventaja de la reducción por choque térmico sobre el pirolítico; por ejemplo, el consumo de energía y la producción de fase sólida; sin embargo, la degradación pirolítica produce un residuo más rico en compuestos de carbono. 


\section{INTRODUCTION}

A tire can be considered a composite material made up of a polymeric matrix multiaxially reinforced with steel wires. Generally, it is composed of natural and/or synthetic rubber; some chemicals such as stabilizers, curatives and processing aids, additives and fillers such as carbon black and silica, and as reinforcement textiles fiberglass and steel wire, mainly, are integrated in the system. In order to display excellent mechanical properties, these components are selected based on their physicochemical properties. The rubber component is mostly formed by constituents such as natural rubber, carbon black, sulphur, accelerators, zinc oxide, stearic acid, retarders, antioxidizers and high aromatics oils, among others [1]. Recycling of rubber tires is not possible by simply melting and reshaping them due to the thermosetting nature of the molecular structure: the crosslinking. The recycling and reutilization of crosslinked elastomers are difficult propositions because of the three dimensional chemical network. This network renders the material insoluble and nonmelting. A tire needs considerable amount of energy to be made -approximately half barrel of crude oil to manufacture a bus tire- and if after its use it is not wisely recycled, it produces ground contamination by being dumped in landfill sites. Nowadays wasted tires have become a major environmental problem. The massive fabrication of tires and the difficulties to make them disappear once they have been used has become a serious environmental problem in the last years around the world. Spent tires, however, comprise valuable material that could be recycled if a proper technique can be developed as it has been demonstrated $[1,2,3]$.

Several methods for recycling tires have been developed [4,5,6]; some of them can convert them in electric and calorific energy. Just like the most of organic compounds, tires decompose with heat by pyrolysis which consists in the decomposition of the organic part by heating (about $400^{\circ} \mathrm{C}$ ) in absence of oxygen. In this process, the type and composition of the final products depend on the properties of the organic material, the temperature, pressure of operation, time of the applied method and the type of gaseous ambient ( $\mathrm{Ar}, \mathrm{N}_{2}$, etc). Among these residuals, the mayor component belongs to carbon black. The pyrolytic carbon black obtained is normally contaminated by various additives of the original tire [7]. Another consequence is that the recovered carbon black is physically different from the original one used as filler in the tires manufacturing. Such dissimilitude is directly related to morphology and structure as well as the particle size and distribution $[8,9]$.

The present investigation attempts to determine the physicochemical characterization of the residual powder obtained from two slightly different processes for rubber tire reduction. Results between the analyses were compared and, finally, a possible use for the powder is discussed.

\section{EXPERIMENTAL PROCEDURE}

Several small pieces were cut from the rubber part of wasted tires having $0.5 \mathrm{~cm} \times 0.5 \mathrm{~cm}$ and about $10 \mathrm{~g}$ weight. These samples were placed in a crucible with lid and then heated in a furnace at an interval of temperatures between $450-750^{\circ} \mathrm{C}$ for $1 \mathrm{hr}$ in presence of nitrogen $\left(\mathrm{N}_{2}\right)$ atmosphere with a $31 / \mathrm{min}$ flow. After this process, the crucibles were cooled down to room temperature and the carbonized samples were manually pulverized with a pestle and mortar. The second method investigated consisted in a thermal shock caused by the rapid change in extreme temperatures. The samples were placed just as before in the crucibles and heated in the furnace, but this time only at $400^{\circ} \mathrm{C}$ during $10 \mathrm{~min}$. After this brief period of time, the samples were immediately immersed in liquid nitrogen $(125 \mathrm{ml})$. After the vaporization of $\mathrm{N}_{2}$, the residue was manually pulverized. Thermal shock was only analyzed at $400^{\circ} \mathrm{C}$ because at higher temperature, the tire rubber initiates full decomposition very similarly to pyrolysis. It was found that $10 \mathrm{~min}$ in the furnace were enough to ensure the breakage of the bonds to obtain a powder residue. 


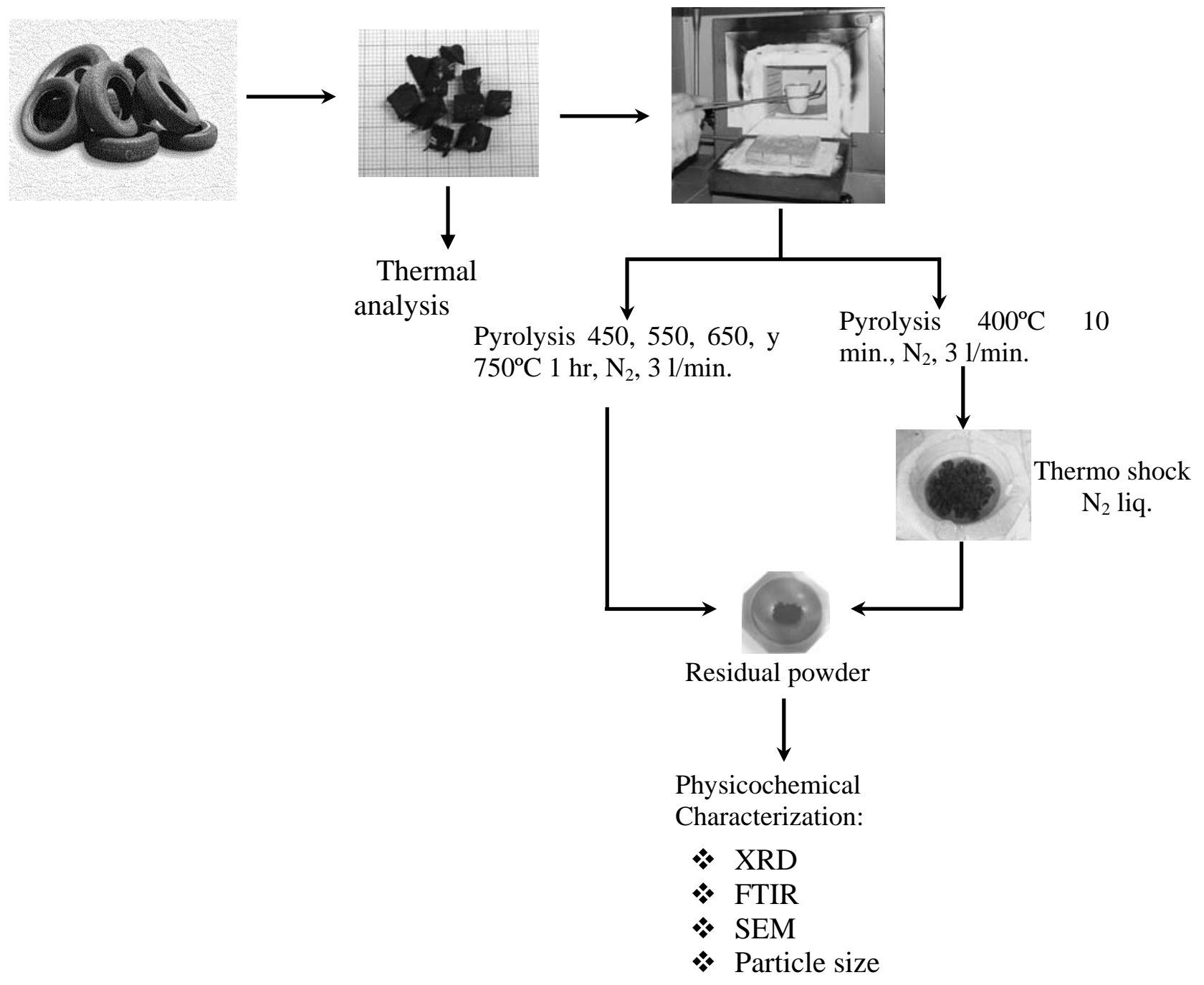

Figure 1. Diagram for pyrolytic and thermal shock processes.

\section{CHARACTERIZATION TECHNIQUES}

\subsection{X-ray diffraction}

In order to characterize the inorganic powders of the residue, they were analyzed using X-ray diffraction. This was carried out in a Siemmens-5000 X-ray diffractometer operated at 40V and 30A, using copperfiltered copper- $K$ radiation with a wavelength of $1.541 \AA$. The diffraction pattern was obtained by scanning the sample in an interval angle of $2 \theta$ from $25^{\circ}$ to $70^{\circ}$ and a rate of $2 / 0.02$ (degrees/s). Experiments were accomplished for sample granules obtained in both reduction processes by placing a few grams of powder in a glass holder for X-ray analysis.

\subsection{Infrared spectroscopy}

Fourier transform infrared spectroscopy (FTIR) analysis was carried out in order to characterize the qualitative organic part of the powder obtained from the two different reduction processes. The analysis was achieved by transmittance technique on a tablet of potassium bromide $(\mathrm{KBr})$ containing the sample in a Thermo Nicolet (Nexus 670-FTIR) spectrophotometer under laboratory conditions of 64 sweeps, with a resolution of $4 \mathrm{~cm}^{-1}$ and a rate of 0.6329 , using a DTGS of $\mathrm{KBr}$ detector in the range of $400-4000$ 
$\mathrm{cm}^{-1}$ (wave number). For the tablet development, $200 \mathrm{mg} \mathrm{KBr}$ previously dried at $80^{\circ} \mathrm{C}$ in an oven vacuum for $24 \mathrm{hrs}$, were weighed and mixed with a small amount of tire powder and then, placed in the dice (tablet hole) and a force of 9 tons was applied for 5 minutes in order to compact the tablet sample. After this, the tablet formed was positioned in the holder and tested.

\subsection{Thermal analysis}

This analysis was carried out to understand the thermal behavior under degradation when samples are heated to high temperatures. A Perkin-Elmer TGA-7 thermogravimetric analyzer (TGA) was used to investigate the thermal stability of the elastomeric section of the tire within a temperature range from $30^{\circ}$ to $800^{\circ} \mathrm{C}$ in a nitrogen atmosphere. The powdered pellets were analyzed at a heating rate of $10^{\circ} \mathrm{C} / \mathrm{min}$. All the experiments were performed in duplicate under a nitrogen atmosphere using samples with a weight of about $7 \mathrm{mg}$.

\subsection{Particle size and distribution}

A Coulter LS100 equipment capable of measuring particle sizes of between 0.1 y $900 \mu$ with ultrasonic sound was used to determine the particle sizes and distribution of the residual powder at different temperatures of pyrolysis. Examined samples weighted about $20 \mathrm{mg}$ approximately and were suspended in water by ultrasound.

\subsection{Scanning Electron Microscopy}

Microscopic analysis was performed on the powder in order to examine the morphology of the particles. A small amount of the uncoated powder pellets was mounted on a metallic slide and the examination was performed with a scanning electron microscopy (SEM) JEOL JSM 6360 LV electron probe microanalyzer at $15 \mathrm{kV}$ in low vacuum.

\section{RESULTS AND DISCUSSION}

Although fairly similar in general, important differences were found among the X-ray diffraction patterns of the solid powders, especially in the intensity of the bands depending on the temperature of pyrolysis. Results obtained by the X-ray diffractograms are presented in Figure 2 for samples obtained by pyrolytic process. Initially, at $450^{\circ} \mathrm{C}$ characteristic peaks corresponding to $\mathrm{ZnO}$ are visible; later, at $550^{\circ} \mathrm{C}$, same peaks appeared slightly diminished indicating some decomposition to give place to the formation of $\alpha$ $\mathrm{ZnS}$. At $650^{\circ} \mathrm{C}$, the plot shows similar peaks attributed to $\alpha-Z n S$ which are more intense at this temperature; at the same time, it is remarkable to denote that the peak corresponding to the organic phase has decreased. At higher temperature of pyrolysis of $750^{\circ} \mathrm{C}$, it is noticeable to observe how the characteristic peaks for $\alpha-Z n S$ are slightly more intense than those presented for $\mathrm{ZnO}$. In agreement to the late statement, it is possible to determine that zinc $(Z n)$ is present in the tires residues principally in form of $\mathrm{ZnO}$, and when the temperature is increased, zinc compounds start to decompose to form $\alpha-\mathrm{ZnS}$ according to the following reaction [4]:

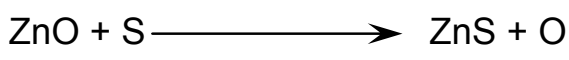




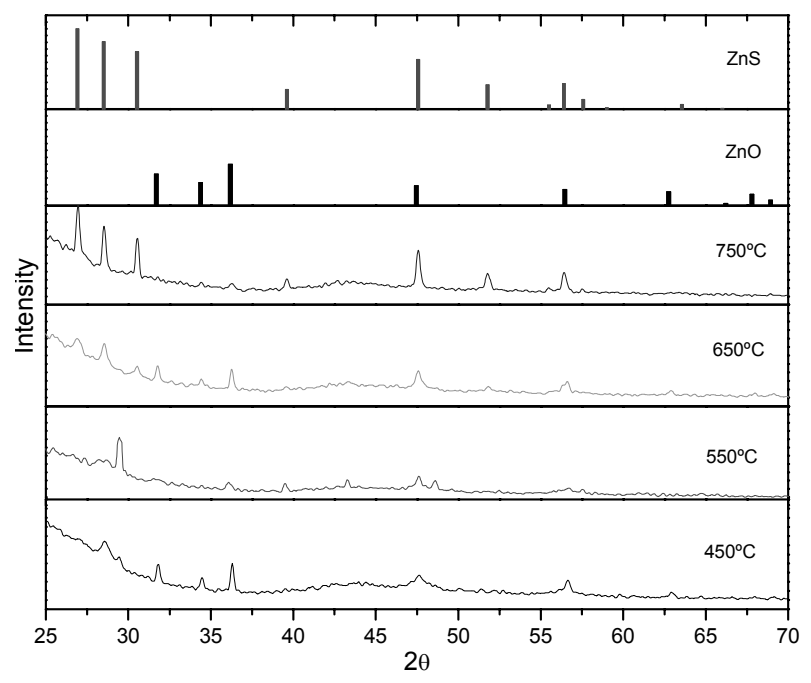

Figure 2. X-ray diffraction for pyrolytic process from $450^{\circ} \mathrm{C}$ to $750^{\circ} \mathrm{C}$.

The X-ray diffractogram for the residues obtained by thermal shock process is presented in

Figure 3 which is very similar to that obtained by pyrolysis at $450^{\circ} \mathrm{C}$. Larger peaks in a range of between 30 and $37(2 \theta)$ correspond to $\mathrm{ZnO}$, apparently because due to the low temperature $\left(400^{\circ} \mathrm{C}\right)$ and lower time inside the furnace $(10 \mathrm{~min}$.), they did not complete the reaction illustrated before. The relative intensities of the main reflections are in good agreement with those reported for zinc oxide ( $\mathrm{ZnO})$. This confirms the presence of the element zinc in the tire, originally forming part of a metal organic zinc compound.

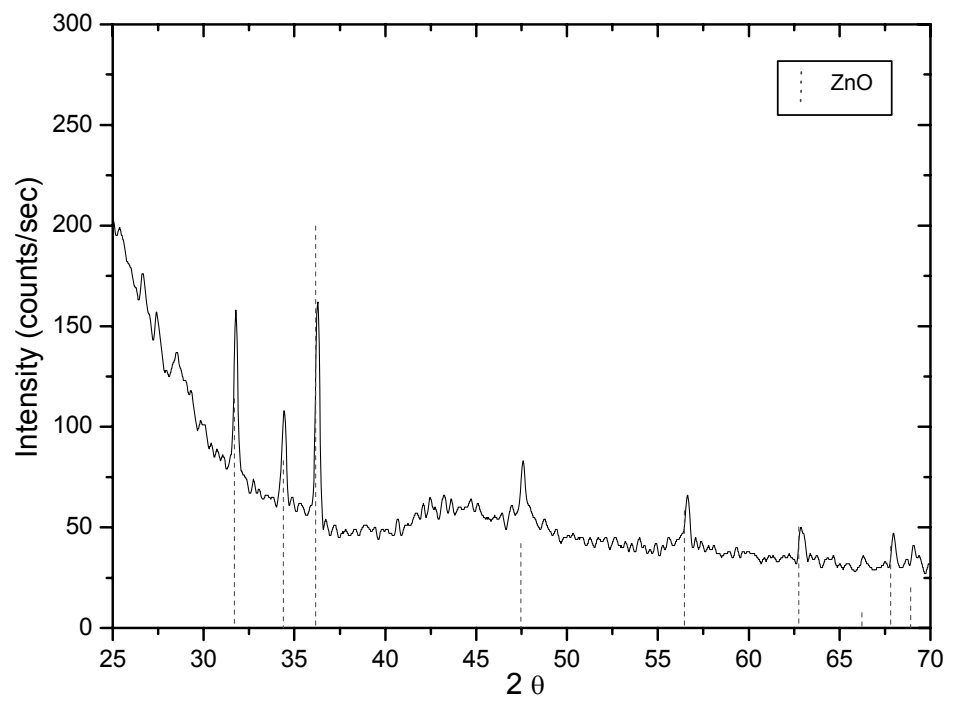

Figure 3. X-ray diffraction for thermal shock process.

As represented in Figure 4, regarding the FTIR experiments, it was found that at low temperature of pyrolysis, signals between 2926 and $2858 \mathrm{~cm}^{-1}$ correspond to methylene $(\mathrm{C}-\mathrm{H}$ asym./sym. Stretch, respectively) while for pyrolized samples at $750^{\circ} \mathrm{C}$, these bands do not appear because at high temperature, tires suffer a complete depolimerization as it was also observed in the thermal analysis by TGA. These results suggest that at higher temperatures of pyrolysis, organic compounds are eliminated remaining mainly inorganic compounds, for example, metallic oxides. The intense band that appears around $3500 \mathrm{~cm}^{-1}$ corresponds with hydroxyl $(\mathrm{OH})$ from the humidity present in all samples. 


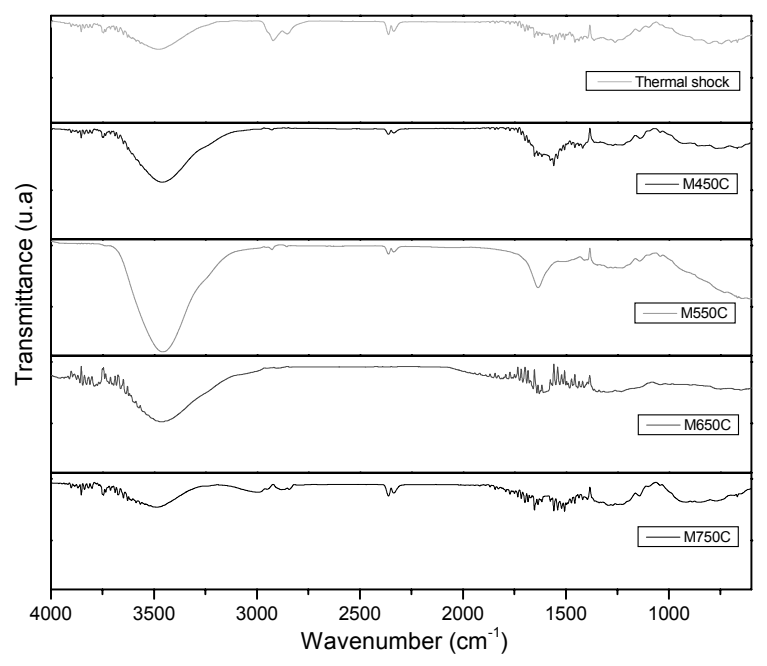

Figure 4. The FTIR spectra for all samples.

Solid powder obtained by thermal shock process was washed with tetrahydrofuran (THF) in order to carry out an extraction of possible organic residuals and the extracted liquid was evaporated. After evaporation, the THF solution developed a yellow film of an elastomeric appearance; therefore, the powder and the film were both characterized separately by FTIR. Figure 5 represents both spectrums where it is possible to observe that the solid residue, after the extraction, exhibits an identical pattern to that found in samples treated by pyrolysis at $750^{\circ} \mathrm{C}$ with almost no signals for organic compounds. On the other hand, the spectrum of the film is similar to that displayed by isoprene with bands corresponding to the vibrations of the group $-\mathrm{CH}_{2}-$ at $2924,2856,1455$ and $1375 \mathrm{~cm}^{-1}$, as well as vibration stretching of polyisoprene groups $\mathrm{C}=\mathrm{C}-$ and $-\mathrm{CH}$ at 1644 and $813 \mathrm{~cm}^{-1}$, respectively. The bands of lesser intensity to these correspond to signals of other compounds and butadiene-styrene residues. This result implies that a tire treated with pyrolysis followed by thermal shock avoids total degradation of the polymeric chain breaking only the sulphur bonds.

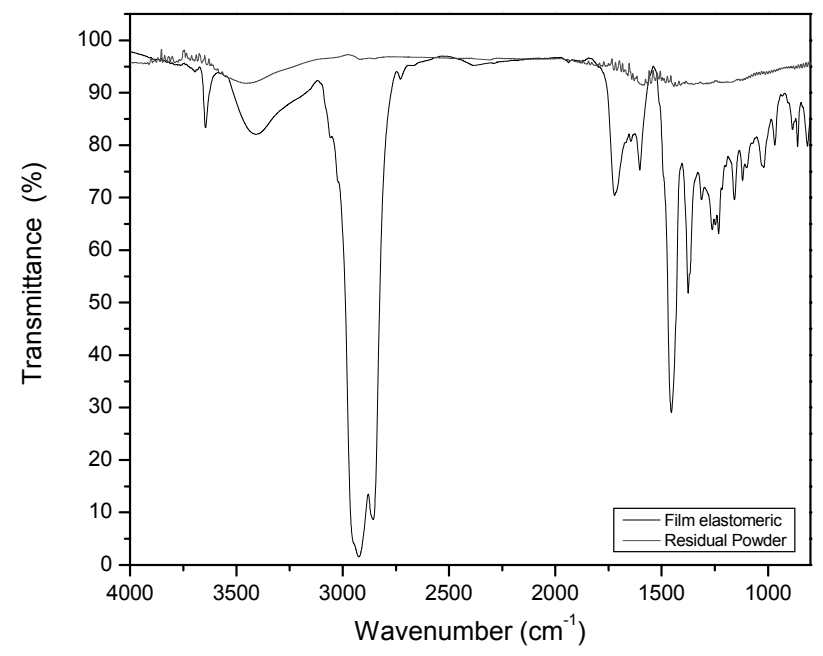

Figure 5. The FTIR spectrum of the film obtained after extraction and the solid residue.

Results for thermal analysis carried out on pieces of the elastomeric part of the wasted tire are presented in Figure 6 where the TGA thermogram is showing the decomposition curve from room temperature to $800^{\circ} \mathrm{C}$. The thermogram shows that there is a small weight loss (ca. $14 \%$ ) below $350^{\circ} \mathrm{C}$ corresponding to loss of water and highly volatile material such as low molecular weight oligomers, plasticizers, 
emulsifications, oils and waxes, antioxidants, etc. that are used for tire manufacture. In the second phase, at between $350^{\circ} \mathrm{C}$ and $500^{\circ} \mathrm{C}$, an abrupt weight loss is observed (ca. $52 \%$ ) attributed to degradation of polymers and medium volatile material including the elastomers, curing agent, processing agents, etc. Finally, the last degradation phase, above $500^{\circ} \mathrm{C}$ only about $34 \%$ of the original weight of the sample is left, corresponding to decomposition products mainly containing $\mathrm{Zn}$ and carbon atoms such as oxidized no-volatile materials, carbon black, graphite, etc. In general, these results suggest that the range of temperatures used during pyrolytic process, except at $450^{\circ} \mathrm{C}$, ensures full organic decomposition remaining only highly inorganic compounds in the solid residue.

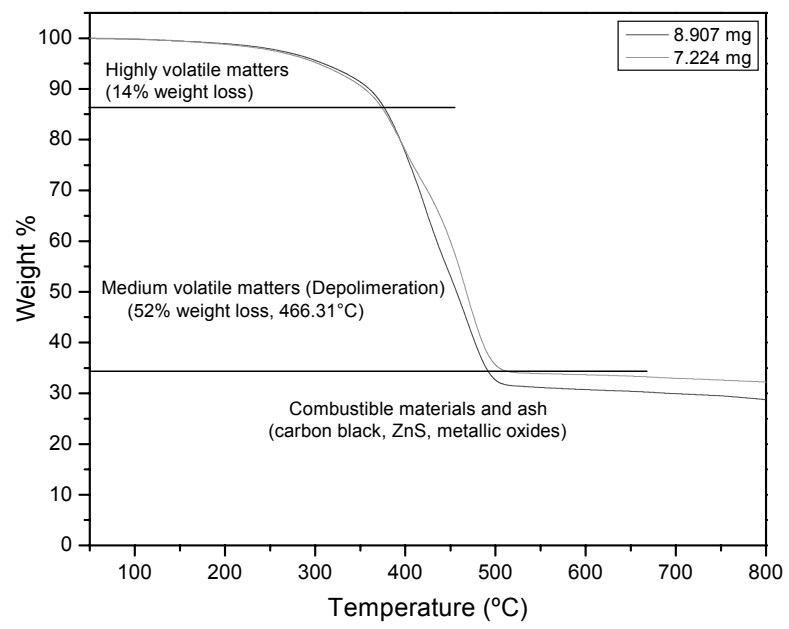

Figure 6. The TGA thermogram of the elastomeric part of the tire.

Distribution of the particle size was studied in order to examine the uniformity or disparity in the dimensions of the solid powder obtained by different processes. The results are presented in Figure 7 where the curves for pyrolysis process at $450^{\circ} \mathrm{C}$ and $750^{\circ} \mathrm{C}$ are compared to the curve acquired for thermal shock process. It is possible to observe the similarity in the three curves even when the two procedures are different, especially in the burning time inside the furnace. Curves initiate with an exponential increment for small sizes from 0 to about $180 \mu \mathrm{m}$ then a maximum appears at about 210 and $250 \mu \mathrm{m}$. Finally, the curves go down towards stabilization at about $600 \mu \mathrm{m}$ and continue to low levels of bigger particles. Invariably, the particle sizes in any process are identical; this could be attributed to the manual pulverization with a pestle and mortar by using the same conditions such as pressure force and time for powdering the solids obtained.

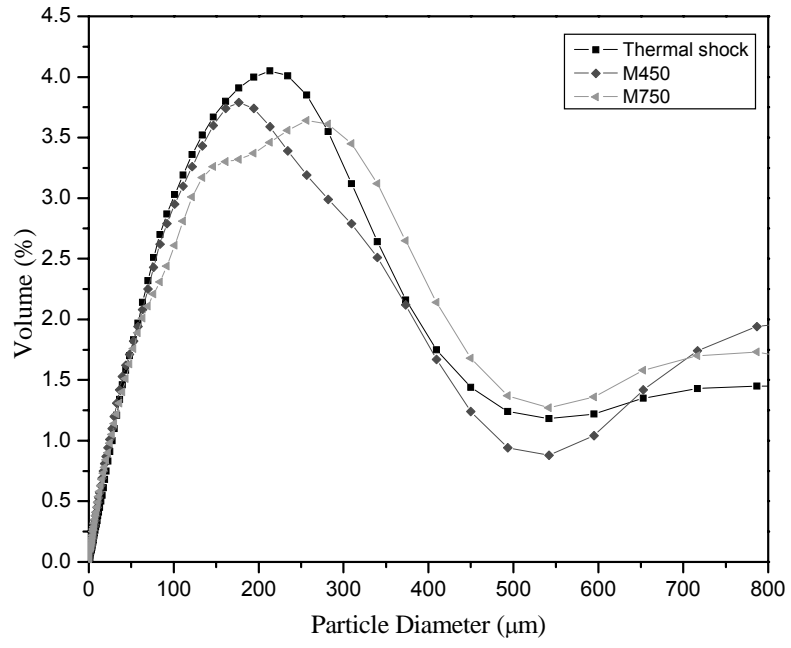

Figure 7. Distribution of the particle size. 
A Scanning Electron Microscope was used to examine the appearance of the solid powder obtained from both processes. Figures 8 (a to e), display the morphology found in some granules of the powdered pellets analyzed under the SEM for samples obtained by pyrolysis at $450^{\circ} \mathrm{C}, 550^{\circ} \mathrm{C}, 650^{\circ} \mathrm{C}, 750^{\circ} \mathrm{C}$ and thermal shock, respectively. Small amorphous granules can be seen dispersed over the area in all cases. It is noticeable the difference in the surface appearance between the grains obtained by both processes. Thermal shock grains seem to be covered by a rubber surface which is due to the remaining organic residue (elastomer) as proved before by FTIR analysis. On the other hand, the granules size is in agreement with the information obtained by the distribution of the particle size where the similarity in the granules dimensions was found despite the temperature of process.

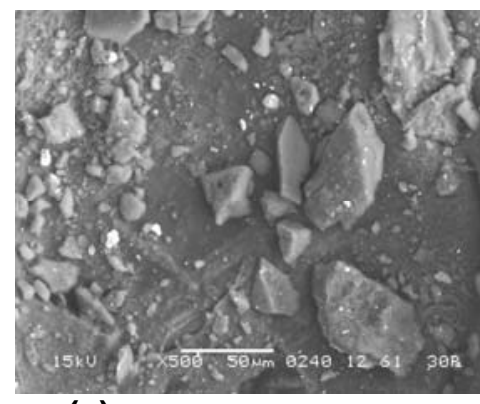

(a)

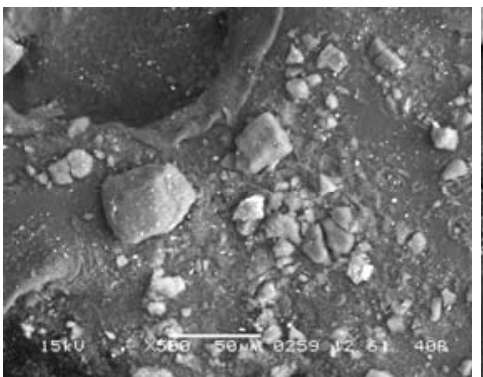

(c)

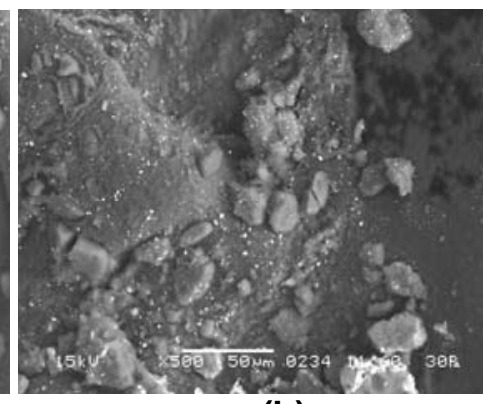

(b)

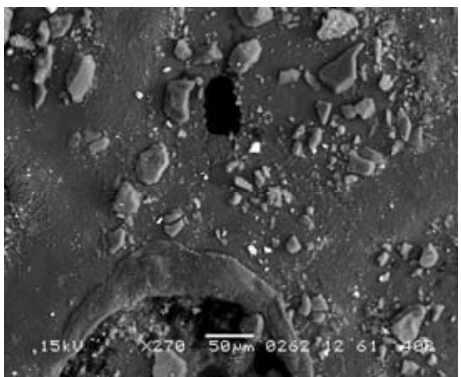

(d)

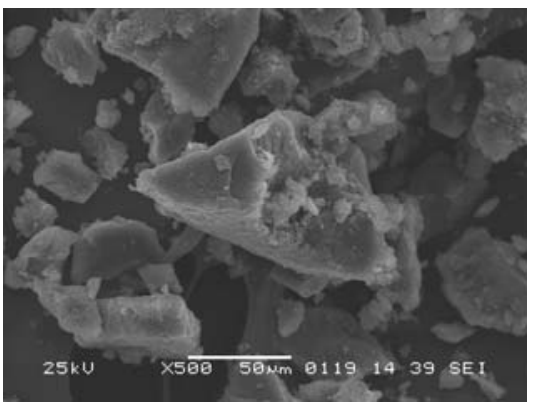

(e)

Figure 8. Micrographs of residual powder: a) $450^{\circ} \mathrm{C}$, b) $550^{\circ} \mathrm{C}$, c) $650^{\circ} \mathrm{C}$, d) $750^{\circ} \mathrm{C}$ and e) thermal shock.

This morphological difference is related to the composition of the residues after de reduction method. As it has been previously mentioned, pyrolysis eliminates organic compounds staying mainly inorganic material which facilitates the pulverization of the remaining solids. On the other hand, by thermal shock, a certain organic composition principally attributed to the elastomer that forms the tire remains. This rubber keeps the particles of the residue united originating the shape observed in the granules. 
However, as it has been demonstrated before, the size distribution of the particles is not significantly affected by the reduction method.

\section{CONCLUSIONS}

Physicochemical characterization of the solid residues obtained by means of two reduction processes, pyrolysis using four different temperatures of burning $\left(450^{\circ} \mathrm{C}, 550^{\circ} \mathrm{C}, 650^{\circ} \mathrm{C}\right.$ and $\left.750^{\circ} \mathrm{C}\right)$ and thermal shock method were performed in order to compare efficiency and viability of both processes as an option for wasted tires control. The results from the X-ray diffraction experiments conducted on all the samples revealed that despite the process, the compounds present in the residues are products mainly containing $\mathrm{Zn}$ and carbon atoms. This analysis showed that the temperature of pyrolysis determines the composition of the final residue containing a higher amount of inorganic material when $750^{\circ} \mathrm{C}$ is used. The presence of the element $\mathrm{Zn}$ in the pellets was also confirmed through this test. By analyzing the samples using FTIR, it was found that by pyrolysis, the organic compounds are not present in the residues when using higher temperature; however, thermal shock process allows reduction of the tire but does not eliminate completely the organic component. By performing an extraction, the presence of a polymeric film corresponding to isoprene was revealed. Thermal analysis exposed the degradation process by high temperature giving as a result the identification of three zones of decomposition for the rubber tire in which about $35 \%$ is the solid remain. Studies of morphology by SEM gave information about the appearance of the granules of the powder after being manually pulverized. The morphology of the granules was not completely spherical but irregularly shaped, with different sizes. The difference in the aspect of the powder observed in pyrolysis and thermal shock is due to the final composition of the granules after each process is undertaken. Particles distribution was similar in both processes with slightly differences at some points; this is due, as explained before, to the method of pulverization. In summary, both processes demonstrated excellent efficiency in reducing the tire, and the characterization revealed the similitude. Nevertheless, the energetic saving favors the thermal shock process even though organic compounds remain in the powder. As a further option, the solid residue can be subsequently used as filler in composite materials [9] where mechanical properties must be deeply studied since each type of powder will behave differently in the final material due to its ultimate composition as commented before.

\section{ACKNOWLEDGEMENTS}

The authors are grateful to the Mexican Council for Science and Technology (CONACYT) for the provision of a studentship for $R$. Mis-Fernandez during this research.

\section{REFERENCES}

[1] Holst O, Stenberg B and Christiansson M, Biotechnological Possibilities for Waste Tyre-Rubber Treatment, Biodegradation. Vol. 9 , 1998. pp. $301-310$

[2] Chaala A, Darmstadt H and Roy C, Acid-Base Method for Demineralization of Pyrolytic Carbon Black, Fuel Processing Technology. Vol. 46, 1996, pp. 1- 15

[3] Pantea D, Darmstadt H, Kaliaguine S and Roy C, Heat-Treatment of Carbon Blacks Obtained by Pyrolysis of Used Tires. Effect on the Surface Chemistry, Porosity and Electrical Conductivity, Journal of Analytical and Applied Pyrolysis. Vol. 67, 2003, pg 55-76.

[4] Roy C, Chaala A and Darmstadt H, The Vacuum Pyrolysis of Used Tires End-Uses for Oil and Carbon Black Products, Journal of Analytical and Applied Pyrolysis, Vol. 51, 1999, pp. 201-221.

[5] Chung $\mathrm{H}$ and Hong $\mathrm{Y}$ K, Scrap Tire/Aggregate Composite: Composition and Primary Characterizations for Pavement Material, Polymer Composites, Vol. 23, No.5, 2002, pp. 852-857. 
[6] Aisien F A, Hymore F K and Ebewele R O, Potential Application of Recycled Rubber in Oil Pollution Control Environmental Monitoring and Assessment, Vol. 85, 2003, pp.175-190.

[7] Darmstadt H, Roy C, Kaliaguine S, Xu G, Auger M, Tuel A and Ramaswamy V, Solid State CNMR Spectroscopy and XRD Studies of Commercial and Pyrolytic Carbon Blacks Carbon. Vol. 38, 2000, pp. 1279-1287

[8] Tripathy A R, Morin J E, Williams D E, Eyles S J, and Farris R J, A Novel Approach to Improving the Mechanical Properties in Recycled Vulcanized Natural Rubber and Its Mechanism, Macromolecules, Vol. 35, 2002, pp. 4616-4627.

[9] Pickering, S J, Recycling Technologies for Thermoset Composite Materials-Current Status, Composites: Part A, Vol. 37, 2006, 1 


\section{Authors Biography}

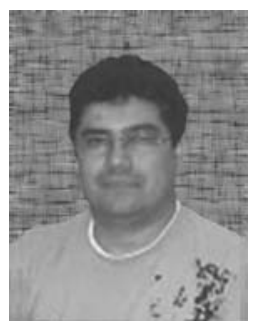

\section{Dr. Carlos Rolando Ríos Soberanis}

He got the B.Sc. in Industrial Chemistry from the Autonomous University of Yucatan (UADY) and the M.Sc. and the Ph.D. in Technology of Advanced Materials from the University of Surrey, England. He is researcher at the Unity of Materials of the Center of Scientific Research of Yucatan (CICY) since 2002.

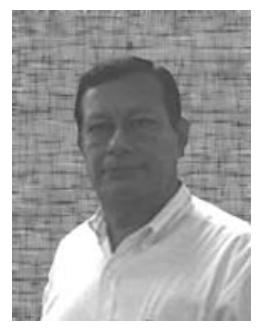

\section{Dr. José Antonio Azamar Barrios}

He got in 1972 the B.Sc. in Chemistry from the School of Chemical Sciences of the Autonomous University of Puebla and the M.Sc. and the Ph.D. in Chemical Sciences in 1994 and 2000, respectively, from the National Autonomous University of Mexico (UNAM). He joined in 1985 the CINVESTAV in Mérida, Yucatán.

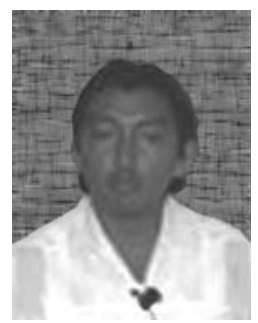

M.C. Ricardo Javier Mis Fernández

He got the B.Sc. in Chemical Engineering from the Faculty of Chemistry of the Autonomous University of Yucatan (UADY) and the M.Sc. in Polymeric Materials from the Center of Scientific Research of Yucatan $(C I C Y)$. 